$\begin{array}{ll}\text { Abstracta Iranica } & \begin{array}{l}\text { Abstracta Iranica } \\ \text { Revue bibliographique pour le domaine irano-aryen }\end{array} \\ & \text { Volume } \mathbf{3 7 - 3 8 - 3 9} \text { | } 2018 \\ & \text { Comptes rendus des publications de 2014-2016 }\end{array}$

\title{
Michael Philip Penn. When Christians First Met Muslims. A Sourcebook of the Earliest Syriac Writings on Islam
}

Florence Jullien

\section{(2) OpenEdition Journals}

Édition électronique

URL : http://journals.openedition.org/abstractairanica/45227

DOI : 10.4000/abstractairanica.45227

ISBN : 1961-960X

ISSN : 1961-960X

Éditeur :

CNRS (UMR 7528 Mondes iraniens et indiens), Éditions de l'IFRI

\section{Référence électronique}

Florence Jullien, « Michael Philip Penn. When Christians First Met Muslims. A Sourcebook of the Earliest Syriac Writings on Islam », Abstracta Iranica [En ligne], Volume 37-38-39 | 2018, document 39, mis en ligne le 30 décembre 2018, consulté le 02 octobre 2020. URL : http://journals.openedition.org/ abstractairanica/45227 ; DOI : https://doi.org/10.4000/abstractairanica.45227

Ce document a été généré automatiquement le 2 octobre 2020.

Tous droits réservés 


\title{
Michael Philip Penn. When Christians First Met Muslims. A Sourcebook of the Earliest Syriac Writings on Islam
}

\author{
Florence Jullien
}

\section{RÉFÉRENCE}

Michael Philip Penn. When Christians First Met Muslims. A Sourcebook of the Earliest Syriac Writings on Islam. Oakland: University of California Press, 2015, 280 p. ISBN

9780520284944

L'A. rassemble l'ensemble des sources syriaques sur les premiers siècles de l'islam et les rencontres entre chrétiens et musulmans dans leur impact; cette documentation produite par des chrétiens contemporains de la conquête islamique et de l'instauration d'un gouvernement musulman est l'une des plus ancienne que nous ayons sur cette période de transition. L'un de ses intérêts est aussi d'offrir une compréhension des événements extérieure aux sources arabes musulmanes. L'ouvrage est présenté comme un «sourcebook» et s'articule logiquement autour de traductions, chacune étant introduite de façon très concise avec des éléments de discussion sur la valeur de la source, des orientations et des informations: critique textuelle, indication des manuscrits existants, valeur du texte pour la problématique générale, date de composition, biographie de l'auteur avec ses engagements confessionnels ou attribution postérieure, etc. De courtes bibliographies correspondant à chaque texte offrent un état de l'art incluant les parutions les plus importantes mais aussi des publications récentes. La référence aux pages des éditions du texte syriaque utilisées par l'A. est signalée chaque fois en marge extérieure, ce qui est utile pour les spécialistes souhaitant vérifier ou travailler sur le texte-source et sa version anglaise. L'explication des options adoptées pour les équivalences terminologiques entre le syriaque et l'anglais dans les versions est donnée dans une petite introduction à l'ouvrage (p. 1-20). Cette collection de traductions est un florilège qui procède d'un 
choix déterminé ; la plupart des textes sont connus par des éditions parfois anciennes. Mais l'A. a eu le souci de rendre compte d'un large éventail de genres littéraires (p. 21-216) : historiographies (Chronique ad annum 637, ad annum 640, Chronique du Huzistān, Chronique maronite, Chronique ad annum 705, Chronique de Jacques d'Édesse, Chronique des catastrophes ad annum 716, Chronique ad annum 724), hagiographies (Vie syriaque de Maxime le Confesseur, Vie de Theodutē), textes exégétiques (exégèse des péricopes de l'Évangile par Ḥenanīšō ${ }^{\mathrm{c}} \mathrm{I}^{\mathrm{er}}$ ) ou homilétiques (Homélies exégétiques de Mār Abba II), scholies (de Jacques d'Édesse), littérature de controverse (Contre les Arméniens de Jacques d'Édesse, Disputatio du patriarche Jean avec l'émir des Agaréens, controverse de Bēth-Ḥālē), littérature canonique (canons issus du synode du catholicos Giwargis I ${ }^{\mathrm{er}}$ ), correspondances (lettres d'ī̌ō yahb III, lettre d'Athanase de Balad, lettres de Jacques d'Édesse), littérature apocalyptique (Apocalypse du Pseudo-Ephrem, Apocalypse du PseudoMéthode, Apocalypse édessénienne, Apocalypse de Jean le Petit) ou d'histoire universelle (Livre des premiers principes ou Les points essentiels de l'histoire du monde temporel de Jean Bar Penkāyē), colophons de manuscrits (ms BL Add. 14 666, ms. BL Add. 14 448) ou inscriptions (de Kāmed el-Lawz, Liban).

2 Ce «sourcebook" peut être considéré comme le corollaire de l'ouvrage de réflexion publié la même année par l'A., Envisioning Islam. Syriac Christians and the Early Muslim World aux Presses de Pennsylvanie; il s'inscrit dans la ligne de l'ouvrage ChristianMuslim Relations: A Bibliographical History, vol. I. 600-900 de D. R. Thomas, B. Roggema, J.P. Monferrer Sala (2009) en offrant un autre éclairage sur les relations entre chrétiens et musulmans, par les textes.

\section{AUTEURS}

\section{FLORENCE JULLIEN}

CNRS, Mondes iranien et indien, Paris 